\title{
Virus Inactivation in Water Using Laser-Induced Graphene Filters
}

Najmul Haque Barbhuiya ${ }^{1}$, Swatantra P. Singh ${ }^{1,2^{*}}$, Arik Makovitzki ${ }^{3}$, Pradnya Narkhede ${ }^{4,5}$, Ziv Oren $^{3}$, Yaakov Adar ${ }^{3}$, Edith Lupu, Lilach Cherry ${ }^{3}$, Arik Monash ${ }^{3}$, and Christopher J. Arnusch ${ }^{5^{*}}$

${ }^{1}$ Environmental Science and Engineering Department (ESED), Indian Institute of Technology Bombay, Mumbai, India

${ }^{2}$ Centre for Research in Nanotechnology \& Science (CRNTS), Indian Institute of Technology Bombay, Mumbai, India

${ }^{3}$ Department of Biotechnology, Israel Institute for Biological Research, Israel

${ }^{4}$ Albert Katz International School for Desert Studies, The Jacob Blaustein Institutes for Desert Research, Ben-Gurion University of the Negev, Sede-Boqer Campus 84990, Israel

${ }^{5}$ Department of Desalination and Water Treatment, The Zuckerberg Institute for Water Research, The Jacob Blaustein Institutes for Desert Research, Ben-Gurion University of the Negev, Sede Boqer Campus, 84990, Israel

*Corresponding authors e-mail: swatantra@iitb.ac.in (SPS) \& $\underline{\operatorname{arnusch} @ \text { bgu.ac.il (CJA) }}$ 


\begin{abstract}
The coronavirus disease (COVID-19) pandemic has significantly increased viral awareness in many fields of research. Development of water treatment technology to combat viral infection by inactivation or disinfection might also play a key role in infection control, as virions are entering drinking water sources. Graphene in the form of laser-induced graphene (LIG) has antimicrobial and antifouling surface effects due to its electrochemical properties and texture, and LIG-based water filters were used for the inactivation of bacteria. However, the antiviral activity of LIGbased filters has not been explored. Here we showed that LIG filters also have antiviral effects under application of electrical potential using the model prototypic poxvirus virus Vaccinia lister. This antiviral activity of the LIG filters was compared with its antibacterial activity, which showed that higher voltages are required for virus inactivation compared to bacteria. The generation of reactive oxygen species, along with surface electrical effects, play a role in the mechanism for the virus inactivation. Thus, the functional LIG filters show potential in water and wastewater treatment for the electrochemical disinfection of various pathogenic microorganisms, including bacteria and viruses.
\end{abstract}

Keywords: Laser-induced graphene; Antiviral; Antibacterial; Disinfection; Conductive filters 


\section{Introduction}

Infectious diseases caused by viruses and bacteria can lead to the death of the host species. ${ }^{1,2}$ Worldwide, viral infections alone claim nearly 15 million human lives annually. ${ }^{3}$ To date, vaccination is considered to be an effective preventive measure against viral infection. However, the lack of effective vaccines against different viruses and their variants combined with the lag time for their development and testing requires other protection measures for the prevention of viral transmission. ${ }^{4}$ Thus, the development of technology that inactivates viruses and bacteria in water and air will prevent viable viruses from entering the host and can help in combating viral infections and limit pandemics. Viruses are generally smaller than bacteria, and they consist of viral nucleic acid protected by a proteinaceous layer called the capsid. In some viruses, the capsid can be enclosed by a protective envelope. Conventional wastewater treatment plants can partially remove viruses like SARS-CoVs, but the safe disposal or reuse of effluent will highly depend on the final disinfection efficacy. ${ }^{5-8}$ Thus, virus disinfection in wastewater might inhibit the indirect infection pathways during outbreaks like SARS-CoVs. ${ }^{5}$ Membrane filtration has the potential to provide a barrier to virus passage; however, electrically conductive surfaces on water filters including graphene can lead to electrochemical surface effects that have been shown to inactivate bacteria and might also cause virus inactivation or removal with no toxic byproducts formation. ${ }^{9}$

Graphene consists of a single layer of $\mathrm{sp}^{2}$-hybridized carbon atoms arranged in a hexagonal lattice fashion. ${ }^{10,11}$ Due to its extraordinary physicochemical properties, graphene, and related derivatives have been used in various applications, ranging from electronics to environmental remediation. ${ }^{12-14}$ Recently, researchers have demonstrated a novel, cost-effective and scalable technique for fabricating graphene coatings on various polymeric materials via laser scribing, called laser-induced graphene (LIG). ${ }^{15,16}$ Some materials suitable for LIG formation are 
commonly used in membrane filtration, ${ }^{15,17,18}$ and the antibacterial and antibiofilm properties of LIG have been explored for water and air filtration. ${ }^{17,19-21}$ Thus, LIG might enhance water treatment technologies and water filtration, and in the present study, we investigate the ability of porous LIG membranes to inactivate viruses.

Many researchers have explored the various mechanisms by which graphene-based filters can inactivate or kill microorganisms. In the absence of electrical potential, graphene has been demonstrated to rupture cell membranes by inducing mechanical stress on direct contact, ${ }^{22-28}$ to sequester microbial cells, ${ }^{23,29-33}$ to cause instability in the cell system due to nanoscale dewetting, ${ }^{34-38}$ or by oxidizing important cellular components ${ }^{14,32,38-45}$ thereby exacerbating cellular death/inactivation. However, these mechanisms require considerable contact time for microbial inactivation and disinfection. On the other hand, in the presence of electrical potential conductive filters can instantly remove, kill or inactivate microorganisms by various mechanisms such as direct and indirect oxidation, Coulombic repulsion, bubble generation, Joule heating, and local $\mathrm{pH}$ change. ${ }^{46-53}$ The electrical conductivity of the conductive filters might also contribute to lipid membrane disruption through the electroporation process. ${ }^{14,54-56}$ Thus the physicochemical and electrochemical manifold effects of graphene, including LIG filters, can potentially also be useful for inactivation of viruses.

In this study, we demonstrate the antiviral ability of LIG filters against the Vaccinia lister virus, a prototypic poxvirus, at different applied potentials. LIG filters were fabricated using polyethersulfone ultrafiltration membranes and used to test inactivation of the virus by conducting plaque assays, and the destructive effects on the virion particles were observed with TEM analysis. We discuss the possible mechanisms of LIG virions inactivation in comparison to the LIG effects on bacteria. The results show that the LIG based conductive filters can be a 
promising candidate in providing high efficiency viral/bacterial disinfection with low energy consumption, which can be explored in different water treatment and membrane filtration processes.

\section{Materials and Methods}

\section{LIG Filter Fabrication}

The LIG membrane filters were fabricated, similarly as described in our previous work. ${ }^{17}$ Briefly, PES (UP150, Microdyn-Nadir, Germany) membranes were lased with a focused laser spot using a VLS 3.50 (Universal Laser Systems) laser platform, which was equipped with a 10.6 $\mu \mathrm{m} \mathrm{CO}_{2}$ pulse laser $(50 \mathrm{~W}, 2.0$ inch Lens Kit). The LIG was obtained with a laser setting of 70 PPI image density, $25 \%$ scan rate, and $0.1 \%$ laser duty cycle, made in the presence of air at ambient conditions. The circular LIG filters were $\sim 200 \mu \mathrm{m}$ thick with a radius of $23 \mathrm{~mm}$. The untreated membranes and the LIG filters were characterized by Raman spectroscopy, X-ray photoelectron spectroscopy (XPS), scanning electron microscopy (SEM), and contact angle measurements, both prior to and after laser modification, as previously described. ${ }^{17}$

\section{Antiviral and antimicrobial activity of LIG filters}

Carbon wires were attached to circular, LIG-coated PES filters using a carbon-based glue. Two LIG electrode filters were stacked on top of one another and placed in a dead-end filtration unit (Fig. S1). Each electrode was connected to a DC voltage supply, and unless otherwise stated, the connections were made such that the anode was situated atop the cathode. A secondary connection was made to a multimeter such that the current through the electrodes could be simultaneously monitored. Bacterial testing was performed as previously described using a bacteria culture mix. ${ }^{17}$ For viral tests, Vaccinia lister in $30 \mathrm{~mL}$ PBS was passed through the conductive LIG filters using a vacuum pump at a constant flow rate of $\sim 1000 \mathrm{~L} \mathrm{~m}^{-2} \mathrm{~h}^{-1}$ in a 
dead-end filtration mode. Then the filter was washed with an additional $30 \mathrm{~mL}$ PBS. The power was adjusted to 2.5, 5.0, 10.0, and $20.0 \mathrm{~V}$ for these filtration experiments. Control experiments in the absence of electrical potential were also performed. The feed and permeate were collected, serially diluted, and the microbes were enumerated using plaque assay for viruses and plate counting methods for bacteria, ${ }^{17}$ respectively. Plaque Assay of Vaccinia Virus-infected Vero cells: In a six-well plate (Costar Corning incorporated, NY, USA) $7 \times 10^{5}$ Vero cells (ATCC CCL-81) suspension at a volume of $3 \mathrm{~mL}$ were plated for each well with DMEM medium supplemented with $10 \%$ heat-inactivated FCS (Biological industries LTD, BET-Haemek, Israel). The cell culture was grown for one day in $37{ }^{\circ} \mathrm{C}, 5 \% \mathrm{CO}_{2}$, to a monolayer. Vaccinia virus standard curve diluted to an estimated concentration of $150-600 \mathrm{PFU} \mathrm{mL}{ }^{-1}$. Then, $0.3 \mathrm{~mL}$ of the virus sample/standard were added to $0.2 \mathrm{~mL}$ medium for each well. The plates were incubated with agitation for $60 \mathrm{~min}$ at $37{ }^{\circ} \mathrm{C}, 5 \% \mathrm{CO}_{2}$, with a relative humidity of $>85 \%$. The medium was removed, and $1 \mathrm{~mL}$ of $0.1 \%$ crystal-violet solution was added and incubated at room temperature for $5 \mathrm{~min}$. The solution was removed, and the cells were washed with water. The plaques were counted manually.

Negative Staining Transmission Electron Microscopy: The drop on the grid method (DEG) was used as follows. A drop $(10 \mu \mathrm{L})$ of the sample suspension containing $10^{5}$ Vaccinia viruses was fixated by incubation with $2.5 \%$ paraformaldehyde (Electron Microscopy Sciences, PA, USA) for $30 \mathrm{~min}$ at $\mathrm{rt}$ followed by another $30 \mathrm{~min}$ incubating at $37^{\circ} \mathrm{C}$. Then, the sample was placed directly onto a glow-discharged EM sample support, 300 MESH copper grid, covered with carbon film (Electron Microscopy Sciences, PA, USA). After adsorption for 10 minutes at room temperature, the grid was washed three times in double-distilled water and negatively stained with $1 \%$ phosphotungstic acid, $\mathrm{pH}$ 4.5. The grids were examined using TECNAI T12 FEI (ThermoFisher, Oragon, USA) transmission electron microscope operated at $200 \mathrm{kV}$. 
Micrographs were recorded with an Erlangsheng 782 ES 500W camera (Gatan, California, USA) at a resolution of $2048 \times 2048$ pixels.

\section{Results and Discussion}

The fabricated LIG filters were characterized using SEM, XPS, and Raman. A detailed explanation of the characterization of the PES LIG filters is provided in our previous work. ${ }^{17}$ Briefly, Raman spectra showed the characteristic D, G, and 2D peaks for graphene at $\sim 1350 \mathrm{~cm}^{-}$

1, $1580 \mathrm{~cm}^{-1}$, and $2700 \mathrm{~cm}^{-1}$, respectively. A high degree of graphene formation and graphitization was supported by the D/G and 2D/G intensity ratios. XPS revealed the chemical composition information of the material surface. It showed C 1s, O 1s, and S $2 p$ peaks at $~ 285.5$, $\sim 534$, and $\sim 167 \mathrm{eV}$, respectively, which was also similar to previous studies. ${ }^{17,57,58}$ This confirmed the presence of C-S bonding in the LIG skeleton, which was absent in the PES membrane substrate. ${ }^{17}$ SEM images showed a highly porous structure for LIG filters. Contactangle measurements were done for unused $\left(39.7 \pm 1.1^{\circ}\right)$ and used LIG filters $\left(30.5 \pm 2.4^{\circ}\right.$ for anodic and $28.4 \pm 0.9^{\circ}$ for cathodic filter). The used cathodic and anodic LIG filters were slightly more hydrophilic than unused filters, supporting the notion of LIG oxidation during filtration (Fig. S2).

\section{Antiviral activity of the LIG filters}

The LIG filters in an anode-on-cathode stacked configuration were used with an externally applied DC voltage for testing their antimicrobial or antiviral activity. The LIG filters were able to inactivate or kill bacteria and virions under the application of different applied voltages (Fig. 1a). A virus containing suspension was filtered through the filters at $2.5 \mathrm{~V}, 5.0 \mathrm{~V}$, 10.0 V, and $20.0 \mathrm{~V}$ at $\sim 1000 \mathrm{~L} \mathrm{~m}^{-2} \mathrm{~h}^{-1}$. Unfiltered suspensions maintained at room temperature during the course of each experiment were used as controls. The application of low electrical 
potentials was not effective in inactivating virions, as shown in Fig. 1a and Fig. 2. Low potentials of $2.5 \mathrm{~V}$ and $5 \mathrm{~V}$ did not cause much damage to the virions, and this was confirmed by the TEM images up to $5 \mathrm{~V}$ (Fig. 2c-d). At this voltage, 40-60\% virus removal was seen, while the same conditions resulted in $100 \%$ bacterial removal (Fig. S3). However, higher electrical potential (10 V) caused significant viral cell damage (Fig. 2e,f), and $~ 92 \%$ virions removal was observed (Fig S6). Further testing at $20 \mathrm{~V}$ resulted in complete inactivation (100\% virus removal) and destruction of the virion was seen (Fig. 2g,h). Virion damage might be because of similar mechanisms described for bacterial inactivation, such as electrical or chemical effects. ${ }^{20}$ However, virions are reported to be more resistant than bacteria towards chemical disinfectants such as chlorine and hydrogen peroxide, ${ }^{59-61}$ and might explain the differences in the activity. $\mathrm{H}_{2} \mathrm{O}_{2}$ and chlorine generation were found to be voltage-dependent, ${ }^{17,20,62}$ which would have increased with increasing voltage, resulting in more indirect oxidation of microbial cellular materials. Also, a higher electric field is required for the electroporation effect in smaller organisms, ${ }^{63}$ and provides a plausible explanation for the relatively higher electrical potential for viral destruction compared to bacteria (Fig. 1c). The transmembrane voltage induced in the cell membrane of the organism, under an applied electric field, is proportional to the size of the organism. Thus, a greater field is required for electroporation of smaller organisms like a virus as compared to bacteria. ${ }^{63,64}$ Moreover, since the number concentration of bacteria and viruses along with the flow rates were approximately the same for both bacterial and virions inactivation, the lower inactivation of virions were also probably due to the smaller size of virions (Fig. 1 b). Here, less contact with the LIG would result in less direct electrical effects, and lower charge transfer and the indirect chemical effects might play a bigger role in the mechanism, seen by the increased voltage requirement for disinfection. ${ }^{63}$ Additionally, an increase in electrical potential can increase the electrophoretic movement of the virions towards the anode, resulting in direct oxidation and increased virus removal because a similar effect was 
seen for bacterial cells. A detailed explanation for these mechanisms of microbial inactivation by LIG electrodes can be found elsewhere. ${ }^{20}$ Briefly, the antimicrobial activity of the LIG filters increases when used as electrode pairs under electrical potentials. The microbial killing possibly involves physical destruction due to contact with LIG, chemical toxicity, or electrical effects of LIG electrodes. The movement of microbes towards LIG surfaces, combined with surface toxicity and generation of localized active chemical species, are the most plausible antimicrobial action mechanisms. Also, the concentration of active chemical species is higher near the electrodes than the bulk solution. Thus, the electrostatic attraction of microbes towards anode further exposes them to a higher concentration of active chemical species. The LIG electrodes may also cause physical damage to the microbe via irreversible electroporation or direct electron transfer. ${ }^{54,63,65,66}$ Taken together, the various antimicrobial effects of conductive LIG filters are also useful to inactivate viruses, but at higher potentials.

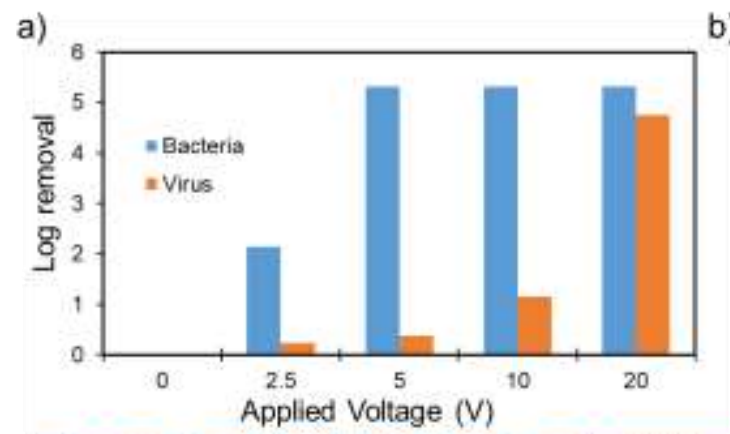

b)

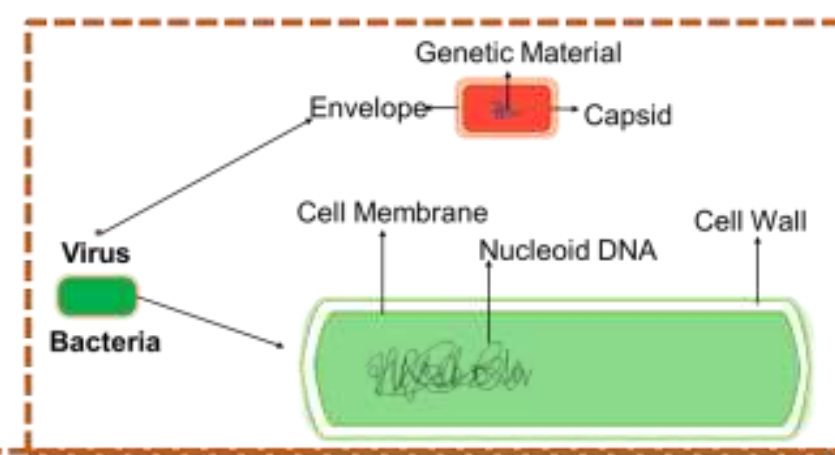

c)

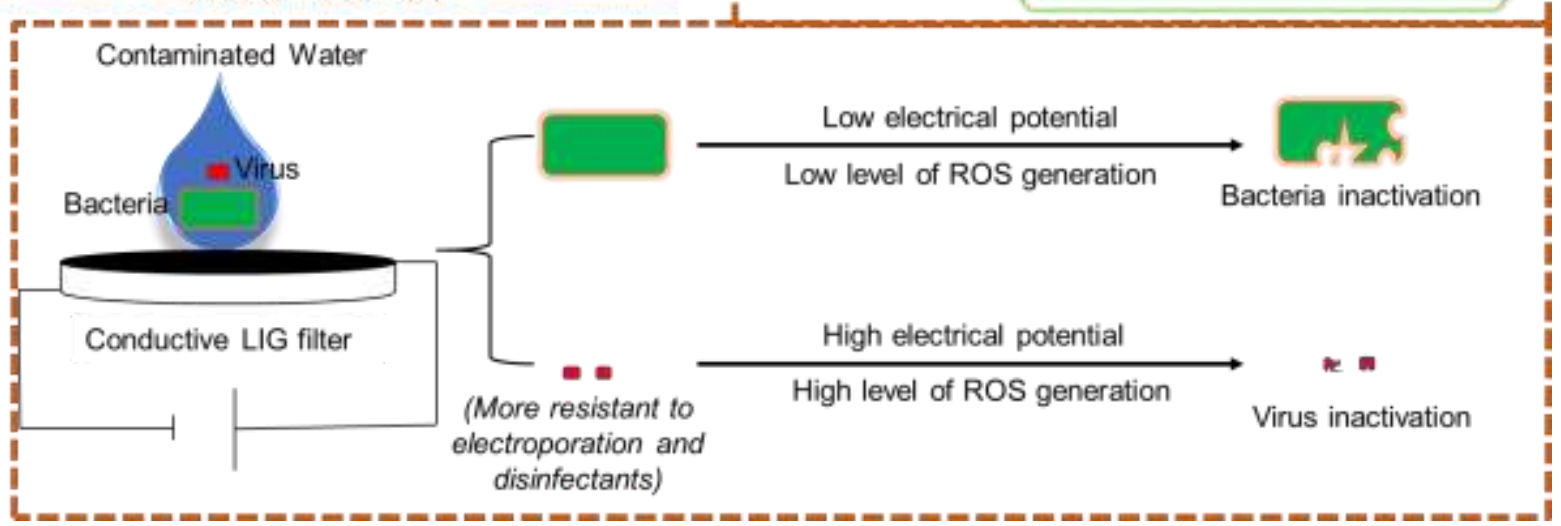


Fig. 1: a) Bacteria and virus inactivation at different voltages at a constant flow rate of $\sim 1000 \mathrm{~L}$ $\mathrm{m}^{-2} \mathrm{~h}^{-1}$; b) Major structural components of the virion and bacteria; c) Proposed mechanism for microbial and viral inactivation.

The voltage-dependent microbicidal efficiency of LIG filters is consistent with the explanation that an increase in the applied potential over the electrodes leads to an associated increase in the electric field and current density. This, in turn, enhances microbial death via electroporation and stimulates redox processes that generate electrochemically active species, which can then participate in oxidative stress-mediated microbial disinfection. ${ }^{20}$ The protective outer layers of microbes are mostly anionic in nature. In virions, the outer capsid surfaces are also generally negatively charged at near-neutral $\mathrm{pH}$ values. ${ }^{67,68}$ The charge densities are affected by the $\mathrm{pH}$, with higher $\mathrm{pH}$ resulting in an increased negative surface charge densities. ${ }^{68}$ As a consequence, microbes are predicted to possess a Coulombic attraction to the positively-charged anode while being repelled by the negatively-charged cathode. This reasoning motivated the placement of the anode above the cathode in the constructed filtration system; the deformation and elongation of cells can occur as they are pulled against the irregular anode surface, thereby affecting membrane rupture and death of the bacteria. $^{20}$ This electrostatically-induced mechanical effect is expected to increase as the externally applied voltage is increased. ${ }^{20}$ Similarly, the virion particles are destroyed at a higher voltage and can be seen in Fig. 2e-h. To confirm that the anode-on-top configuration of LIG filters is most effective, antimicrobial activity was evaluated as previously, except with the cathodic filter situated above the LIG anode. However, the cathode-on-top configuration of filters was only slightly less effective at microbial killing (Table S1). 

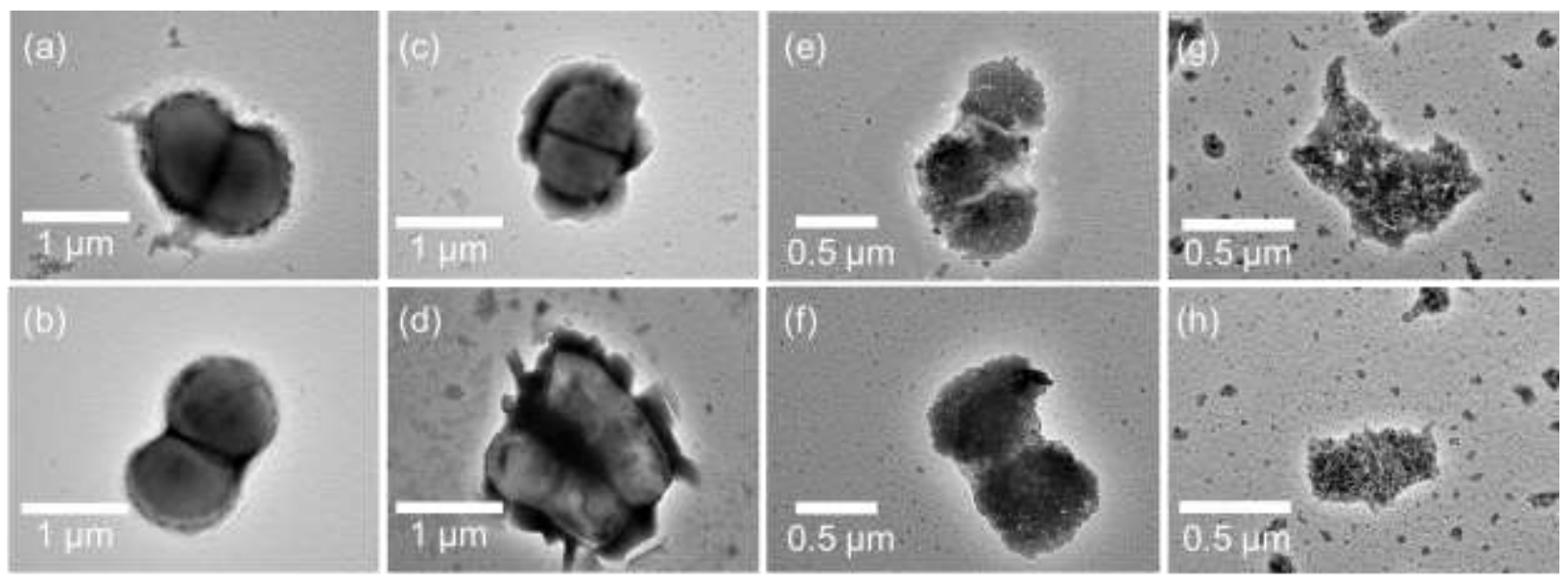

Fig. 2. TEM images of the virions inactivated at different voltages: (a,b) $0 \mathrm{~V}$; (c,d) $5 \mathrm{~V}$; (e,f) 10 $\mathrm{V} ;(\mathrm{g}, \mathrm{h}) 20 \mathrm{~V}$.

\section{Current-voltage relationships present in LIG-PES filters}

The high surface area and exceptional intrinsic charge-carrier mobility of LIG filters permit the establishment of high current densities from relatively low voltages, allowing for the rapid and energy-efficient killing of virions via electrical contact and the formation of redoxactive chemical species such as $\mathrm{H}_{2} \mathrm{O}_{2}$ at the lower, cathodic filter and $\mathrm{Cl}_{2}$ at the upper, anodic filter seen in the following equations:

$$
\begin{aligned}
& 2 \mathrm{Cl}^{-}(a q) \rightarrow 2 \mathrm{Cl}_{2}(g)+2 e^{-} \\
& \mathrm{O}_{2}(g)+2 \mathrm{H}^{+}(a q)+2 e^{-} \rightarrow \mathrm{H}_{2} \mathrm{O}_{2}(a q)
\end{aligned}
$$

The current-voltage relationship for the LIG filters used during experimentation was elucidated using $0.9 \% \mathrm{NaCl}$ solution (Table S2). As predicted, the extensive surface area of the LIG filters leads to the generation of large currents and can enhance electrochemical processes even at low voltages. ${ }^{20}$ The filters are therefore expected to yield high wastewater disinfection rates during filtration. 


\section{Conclusions}

Virions and bacteria present in water supplies pose imminent threats to human health, agricultural productivity, and other spheres of society. The increase in evidence for the presence of viral RNAs in wastewater is also increasing concern. Recent studies related to viral infection and pandemics like SARS-CoVs have emphasized the need for better virion disinfection efficiencies for wastewater effluents. Low-pressure membrane filtrations have been suggested as an advanced technology to prevent such virion's dissemination. Surface modifications of the membranes can further increase the virion removal via electrostatic and hydrophobic interactions. The development of electrically conducting membranes or filters with active and passive antimicrobial and anti-biofouling properties as well as low energy inputs stands to revolutionize water treatment systems worldwide, bearing both economic and environmental benefits. Here we demonstrated the antiviral activity of the conductive LIG filters and show that virions such as the Vaccinia virus are more resistant to electrochemical disinfection than their bacterial counterparts; however, the application of higher potentials up to $20 \mathrm{~V}$ provided complete inactivation of virions. LIG-integrated membranes may hold the key to building the next generation of cost-effective systems for simultaneous water filtration and disinfection of pathogenic microbes, including bacteria and viruses.

\section{References:}

(1) Gerba, C. P.; Betancourt, W. Q. Viral Aggregation: Impact on Virus Behavior in the Environment. Environmental Science and Technology. American Chemical Society July 2017, pp 7318-7325. https://doi.org/10.1021/acs.est.6b05835.

(2) Rivera, A.; Messaoudi, I. Pathophysiology of Ebola Virus Infection: Current Challenges and Future Hopes. ACS Infectious Diseases. American Chemical Society May 2015, pp 186-197. https://doi.org/10.1021/id5000426.

(3) Morens, D. M.; Folkers, G. K.; Fauci, A. S. The Challenge of Emerging and Re-Emerging Infectious Diseases. Nature. Nature Publishing Group July 2004, pp 242-249. https://doi.org/10.1038/nature02759. 
(4) Webby, R.; Hoffmann, E.; Webster, R. Molecular Constraints to Interspecies Transmission of Viral Pathogens. Nature Medicine. Nature Publishing Group 2004, pp S77-S81. https://doi.org/10.1038/nm1151.

(5) Bogler, A.; Packman, A.; Furman, A.; Gross, A.; Kushmaro, A.; Ronen, A.; Dagot, C.; Hill, C.; Vaizel-Ohayon, D.; Morgenroth, E.; et al. Rethinking Wastewater Risks and Monitoring in Light of the COVID-19 Pandemic. Nat. Sustain. 2020, 1-10. https://doi.org/10.1038/s41893-020-006052 .

(6) Naddeo, V.; Liu, H. Editorial Perspectives: 2019 Novel Coronavirus (SARS-CoV-2): What Is Its Fate in Urban Water Cycle and How Can the Water Research Community Respond?

Environmental Science: Water Research and Technology. Royal Society of Chemistry May 2020, pp 1213-1216. https://doi.org/10.1039/d0ew90015j.

(7) Wigginton, K. R.; Ye, Y.; Ellenberg, R. M. Emerging Investigators Series: The Source and Fate of Pandemic Viruses in the Urban Water Cycle. Environmental Science: Water Research and Technology. Royal Society of Chemistry November 2015, pp 735-746. https://doi.org/10.1039/c5ew00125k.

(8) Qiu, Y.; Lee, B. E.; Neumann, N.; Ashbolt, N.; Craik, S.; Maal-Bared, R.; Pang, X. L. Assessment of Human Virus Removal during Municipal Wastewater Treatment in Edmonton, Canada. J. Appl. Microbiol. 2015, 119 (6), 1729-1739. https://doi.org/10.1111/jam.12971.

(9) Krasner, S. W.; Weinberg, H. S.; Richardson, S. D.; Pastor, S. J.; Chinn, R.; Sclimenti, M. J.; Onstad, G. D.; Thruston, A. D. Occurrence of a New Generation of Disinfection Byproducts. Environ. Sci. Technol. 2006, 40 (23), 7175-7185. https://doi.org/10.1021/es060353j.

(10) Geim, A. K.; Novoselov, K. S. The Rise of Graphene. Nat. Mater. 2007, 6 (3), 183-191. https://doi.org/10.1038/nmat1849.

(11) Allen, M. J.; Tung, V. C.; Kaner, R. B. Honeycomb Carbon: A Review of Graphene. Chem. Rev. 2010. https://doi.org/10.1021/cr900070d.

(12) Wang, X.; Zhang, Y.; Zhi, C.; Wang, X.; Tang, D.; Xu, Y.; Weng, Q.; Jiang, X.; Mitome, M.; Golberg, D.; et al. Three-Dimensional Strutted Graphene Grown by Substrate-Free Sugar Blowing for High-Power-Density Supercapacitors. Nat. Commun. 2013, 4 (1), 1-8.

https://doi.org/10.1038/ncomms3905.

(13) Bitounis, D.; Ali-Boucetta, H.; Hong, B. H.; Min, D.-H.; Kostarelos, K. Prospects and Challenges of Graphene in Biomedical Applications. Adv. Mater. 2013, 25 (16), 2258-2268. https://doi.org/10.1002/adma.201203700.

(14) Perreault, F.; Fonseca de Faria, A.; Elimelech, M. Environmental Applications of Graphene-Based Nanomaterials. Chem. Soc. Rev. 2015, 44 (16), 5861-5896. https://doi.org/10.1039/C5CS00021A.

(15) Lin, J.; Peng, Z.; Liu, Y.; Ruiz-Zepeda, F.; Ye, R.; Samuel, E. L. G.; Yacaman, M. J.; Yakobson, B. I.; Tour, J. M. Laser-Induced Porous Graphene Films from Commercial Polymers. Nat. Commun. 2014, 5, 5714 (1-8). https://doi.org/10.1038/ncomms6714.

(16) Chyan, Y.; Ye, R.; Li, Y.; Singh, S. P.; Arnusch, C. J.; Tour, J. M. Laser-Induced Graphene by Multiple Lasing: Toward Electronics on Cloth, Paper, and Food. ACS Nano 2018, 12 (3), 21762183. https://doi.org/10.1021/acsnano.7b08539.

(17) Singh, S. P.; Li, Y.; Zhang, J.; Tour, J. M.; Arnusch, C. J. Sulfur-Doped Laser-Induced Porous Graphene Derived from Polysulfone-Class Polymers and Membranes. ACS Nano 2018, 12 (1), 289-297. https://doi.org/10.1021/acsnano.7b06263.

(18) Chyan, Y.; Ye, R.; Li, Y.; Singh, S. P.; Arnusch, C. J.; Tour, J. M. Laser-Induced Graphene by Multiple Lasing: Toward Electronics on Cloth, Paper, and Food. ACS Nano 2018, 12 (3), 21762183. https://doi.org/10.1021/acsnano.7b08539.

(19) Singh, S. P.; Ramanan, S.; Kaufman, Y.; Arnusch, C. J. Laser-Induced Graphene Biofilm Inhibition: Texture Does Matter. ACS Appl. Nano Mater. 2018, 1 (4), 1713-1720. https://doi.org/10.1021/acsanm.8b00175.

(20) Singh, S. P.; Li, Y.; Be 'er, A.; Oren, Y.; Tour, J. M.; Arnusch, C. J. Laser-Induced Graphene Layers and Electrodes Prevents Microbial Fouling and Exerts Antimicrobial Action. ACS Appl. Mater. Interfaces 2017, 9 (21), 18238-18247. https://doi.org/10.1021/acsami.7b04863.

(21) Stanford, M. G.; Li, J. T.; Chen, Y.; Mchugh, E. A.; Liopo, A.; Xiao, H.; Tour, J. M. Self- 
Sterilizing Laser-Induced Graphene Bacterial Air Filter. ACS Nano 2019, 13 (10), 11912-11920. https://doi.org/10.1021/acsnano.9b05983.

(22) Mejías Carpio, I. E.; Santos, C. M.; Wei, X.; Rodrigues, D. F. Toxicity of a Polymer-Graphene Oxide Composite against Bacterial Planktonic Cells, Biofilms, and Mammalian Cells. Nanoscale 2012, 4 (15), 4746-4756. https://doi.org/10.1039/c2nr30774j.

(23) Dallavalle, M.; Calvaresi, M.; Bottoni, A.; Melle-Franco, M.; Zerbetto, F. Graphene Can Wreak Havoc with Cell Membranes. ACS Appl. Mater. Interfaces 2015, 7 (7), 4406-4414. https://doi.org/10.1021/am508938u.

(24) Wang, J.; Wei, Y.; Shi, X.; Gao, H. Cellular Entry of Graphene Nanosheets: The Role of Thickness, Oxidation and Surface Adsorption. RSC Adv. 2013, 3 (36), 15776-15782. https://doi.org/10.1039/c3ra40392k.

(25) Li, Y.; Yuan, H.; Von Dem Bussche, A.; Creighton, M.; Hurt, R. H.; Kane, A. B.; Gao, H. Graphene Microsheets Enter Cells through Spontaneous Membrane Penetration at Edge Asperities and Corner Sites. Proc. Natl. Acad. Sci. U. S. A. 2013, 110 (30), 12295-12300. https://doi.org/10.1073/pnas.1222276110.

(26) Hu, W.; Peng, C.; Luo, W.; Lv, M.; Li, X.; Li, D.; Huang, Q.; Fan, C. Graphene-Based Antibacterial Paper. https://doi.org/10.1021/nn101097v.

(27) Pham, V. T. H.; Truong, V. K.; Quinn, M. D. J.; Notley, S. M.; Guo, Y.; Baulin, V. A.; Kobaisi, M. Al; Crawford, R. J.; Ivanova, E. P. Graphene Induces Formation of Pores That Kill Spherical and Rod-Shaped Bacteria. 2015, No. 8, 8458-8467. https://doi.org/10.1021/acsnano.5b03368.

(28) Tu, Y.; Lv, M.; Xiu, P.; Huynh, T.; Zhang, M.; Castelli, M.; Liu, Z.; Huang, Q.; Fan, C.; Fang, H.; et al. Destructive Extraction of Phospholipids from Escherichia Coli Membranes by Graphene Nanosheets. Nat. Nanotechnol. 2013, 8 (8), 594-601. https://doi.org/10.1038/nnano.2013.125.

(29) Chen, J.; Peng, H.; Wang, X.; Shao, F.; Yuan, Z.; Han, H. Graphene Oxide Exhibits BroadSpectrum Antimicrobial Activity against Bacterial Phytopathogens and Fungal Conidia by Intertwining and Membrane Perturbation. Nanoscale 2014, 6 (3), 1879-1889. https://doi.org/10.1039/C3NR04941H.

(30) Liu, S.; Hu, M.; Zeng, T. H.; Wu, R.; Jiang, R.; Wei, J.; Wang, L.; Kong, J.; Chen, Y. Lateral Dimension-Dependent Antibacterial Activity of Graphene Oxide Sheets. Langmuir 2012, 28, 12364-12372. https://doi.org/10.1021/la3023908.

(31) Akhavan, O.; Ghaderi, E.; Esfandiar, A. Wrapping Bacteria by Graphene Nanosheets for Isolation from Environment, Reactivation by Sonication, and Inactivation by near-Infrared Irradiation. $J$. Phys. Chem. B 2011, 115 (19), 6279-6288. https://doi.org/10.1021/jp200686k.

(32) Perreault, F.; De Faria, A. F.; Nejati, S.; Elimelech, M. Antimicrobial Properties of Graphene Oxide Nanosheets: Why Size Matters. ACS Nano 2015, 9 (7), 7226-7236. https://doi.org/10.1021/acsnano.5b02067.

(33) Liu, S.; Zeng, T. H.; Hofmann, M.; Burcombe, E.; Wei, J.; Jiang, R.; Kong, J.; Chen, Y. Antibacterial Activity of Graphite, Graphite Oxide, Graphene Oxide, and Reduced Graphene Oxide: Membrane and Oxidative Stress. ACS Nano 2011, 5 (9), 6971-6980. https://doi.org/10.1021/nn202451x.

(34) Berne, B. J.; Weeks, J. D.; Zhou, R. Dewetting and Hydrophobic Interaction in Physical and Biological Systems. Annu. Rev. Phys. Chem. 2009, 60 (1), 85-103. https://doi.org/10.1146/annurev.physchem.58.032806.104445.

(35) Zhou, R.; Huang, X.; Margulis, C. J.; Berne, B. J. Hydrophobic Collapse in Multidomain Protein Folding. Science (80-. ). 2004, 305 (5690), 1605-1609. https://doi.org/10.1126/science.1101176.

(36) Liu, P.; Huang, X.; Zhou, R.; Berne, B. J. Observation of a Dewetting Transition in the Collapse of the Melittin Tetramer. Nature 2005, 437 (7055), 159-162. https://doi.org/10.1038/nature03926.

(37) Luan, B.; Huynh, T.; Zhao, L.; Zhou, R. Potential Toxicity of Graphene to Cell Functions via Disrupting Protein-Protein Interactions. ACS Nano 2015, 9 (1), 663-669. https://doi.org/10.1021/nn506011j.

(38) Zhang, Y.; Ali, S. F.; Dervishi, E.; Xu, Y.; Li, Z.; Casciano, D.; Biris, A. S. Cytotoxicity Effects of Graphene and Single-Wall Carbon Nanotubes in Neural Phaeochromocytoma-Derived Pc12 Cells. ACS Nano 2010, 4 (6), 3181-3186. https://doi.org/10.1021/nn1007176. 
(39) Gurunathan, S.; Han, J. W.; Abdal Dayem, A.; Eppakayala, V.; Kim, J. H. Oxidative StressMediated Antibacterial Activity of Graphene Oxide and Reduced Graphene Oxide in Pseudomonas Aeruginosa. Int. J. Nanomedicine 2012, 7, 5901-5914. https://doi.org/10.2147/IJN.S37397.

(40) Ligaya, Y.; Musico, F.; Santos, C. M.; Lourdes, M.; Dalida, P.; Rodrigues, D. F. Surface Modification of Membrane Filters Using Graphene and Graphene Oxide-Based Nanomaterials for Bacterial Inactivation and Removal. ACS Sustain. Chem. Eng. 2014, 2, 1559-1565. https://doi.org/10.1021/sc500044p.

(41) Romero-Vargas Castrillón, S.; Perreault, F.; De Faria, A. F.; Elimelech, M. Interaction of Graphene Oxide with Bacterial Cell Membranes: Insights from Force Spectroscopy. Environ. Sci. Technol. Lett. 2015, 2 (4), 112-117. https://doi.org/10.1021/acs.estlett.5b00066.

(42) Liu, X.; Sen, S.; Liu, J.; Kulaots, I.; Geohegan, D.; Kane, A.; Puretzky, A. A.; Rouleau, C. M.; More, K. L.; Palmore, G. T. R.; et al. Antioxidant Deactivation on Graphenic Nanocarbon Surfaces. Small 2011, 7 (19), 2775-2785. https://doi.org/10.1002/smll.201100651.

(43) Chen, J.; Wang, X.; Han, H. A New Function of Graphene Oxide Emerges: Inactivating Phytopathogenic Bacterium Xanthomonas Oryzae Pv. Oryzae. J. Nanoparticle Res. 2013, 15 (5), 1-14. https://doi.org/10.1007/s11051-013-1658-6.

(44) Nanda, S. S.; An, S. S. A.; Yi, D. K. Oxidative Stress and Antibacterial Properties of a Graphene Oxide-Cystamine Nanohybrid. Int. J. Nanomedicine 2015, 10, 549-556.

https://doi.org/10.2147/IJN.S75768.

(45) Li, Y.; Liu, Y.; Fu, Y.; Wei, T.; Le Guyader, L.; Gao, G.; Liu, R. S.; Chang, Y. Z.; Chen, C. The Triggering of Apoptosis in Macrophages by Pristine Graphene through the MAPK and TGF-Beta Signaling Pathways. Biomaterials 2012, 33 (2), 402-411.

https://doi.org/10.1016/j.biomaterials.2011.09.091.

(46) Ahmed, F.; Lalia, B. S.; Kochkodan, V.; Hilal, N.; Hashaikeh, R. Electrically Conductive Polymeric Membranes for Fouling Prevention and Detection: A Review. Desalination. Elsevier B.V. August 2016, pp 1-15. https://doi.org/10.1016/j.desal.2016.01.030.

(47) Shim, S.; Hong, S. H.; Tak, Y.; Yoon, J. Prevention of Pseudomonas Aeruginosa Adhesion by Electric Currents. Biofouling 2011, 27 (2), 217-224.

https://doi.org/10.1080/08927014.2011.554831.

(48) Vecitis, C. D.; Schnoor, M. H.; Rahaman, M. S.; Schiffman, J. D.; Elimelech, M. Electrochemical Multiwalled Carbon Nanotube Filter for Viral and Bacterial Removal and Inactivation. Environ. Sci. Technol. 2011, 45 (8), 3672-3679. https://doi.org/10.1021/es2000062.

(49) Chaplin, B. P. Critical Review of Electrochemical Advanced Oxidation Processes for Water Treatment Applications. Environmental Sciences: Processes and Impacts. 2014, pp 1182-1203. https://doi.org/10.1039/c3em00679d.

(50) Istanbullu, O.; Babauta, J.; Duc Nguyen, H.; Beyenal, H. Electrochemical Biofilm Control: Mechanism of Action. Biofouling 2012, 28 (8), 769-778. https://doi.org/10.1080/08927014.2012.707651.

(51) Asadi, M. R.; Torkaman, G. Bacterial Inhibition by Electrical Stimulation. Adv. Wound Care 2014, 3 (2), 91-97. https://doi.org/10.1089/wound.2012.0410.

(52) Duan, W.; Dudchenko, A.; Mende, E.; Flyer, C.; Zhu, X.; Jassby, D. Electrochemical Mineral Scale Prevention and Removal on Electrically Conducting Carbon Nanotube-Polyamide Reverse Osmosis Membranes. Environ. Sci. Process. Impacts 2014, 16 (6), 1300-1308. https://doi.org/10.1039/c3em00635b.

(53) Tang, L.; Iddya, A.; Zhu, X.; Dudchenko, A. V.; Duan, W.; Turchi, C.; Vanneste, J.; Cath, T. Y.; Jassby, D. Enhanced Flux and Electrochemical Cleaning of Silicate Scaling on Carbon NanotubeCoated Membrane Distillation Membranes Treating Geothermal Brines. ACS Appl. Mater. Interfaces 2017, 9 (44), 38594-38605. https://doi.org/10.1021/acsami.7b12615.

(54) Tsong, T. Y. Electroporation of Cell Membranes. In Electroporation and Electrofusion in Cell Biology; Springer US, 1989; pp 149-163. https://doi.org/10.1007/978-1-4899-2528-2_9.

(55) Wang, Y.; El-Deen, A. G.; Li, P.; Oh, B. H. L.; Guo, Z.; Khin, M. M.; Vikhe, Y. S.; Wang, J.; Hu, R. G.; Boom, R. M.; et al. High-Performance Capacitive Deionization Disinfection of Water with 
Graphene Oxide-Graft-Quaternized Chitosan Nanohybrid Electrode Coating. ACS Nano 2015, 9 (10), 10142-10157. https://doi.org/10.1021/acsnano.5b03763.

(56) Liu, C.; Xie, X.; Zhao, W.; Liu, N.; Maraccini, P. A.; Sassoubre, L. M.; Boehm, A. B.; Cui, Y. Conducting Nanosponge Electroporation for Affordable and High-Efficiency Disinfection of Bacteria and Viruses in Water. Nano Lett. 2013, 13 (9), 4288-4293. https://doi.org/10.1021/n1402053z.

(57) Thakur, A. K.; Singh, S. P.; Kleinberg, M. N.; Gupta, A.; Arnusch, C. J. Laser-Induced GraphenePVA Composites as Robust Electrically Conductive Water Treatment Membranes. ACS Appl. Mater. Interfaces 2019, 11 (11), 10914-10921. https://doi.org/10.1021/acsami.9b00510.

(58) Thakur, A. K.; Singh, S. P.; Thamaraiselvan, C.; Kleinberg, M. N.; Arnusch, C. J. Graphene Oxide on Laser-Induced Graphene Filters for Antifouling, Electrically Conductive Ultrafiltration Membranes. J. Memb. Sci. 2019, 591, 117322. https://doi.org/10.1016/j.memsci.2019.117322.

(59) Drees, K. P.; Abbaszadegan, M.; Maier, R. M. Comparative Electrochemical Inactivation of Bacteria and Bacteriophage. Water Res. 2003, 37 (10), 2291-2300. https://doi.org/10.1016/S00431354(03)00009-5.

(60) Asghari, A. The Inactivation of Bacteria and Viruses by Hydrogen Peroxide, University of Florida, 1993.

(61) Tree, J. A.; Adams, M. R.; Lees, D. N. Chlorination of Indicator Bacteria and Viruses in Primary Sewage Effluent. Appl. Environ. Microbiol. 2003, 69 (4), 2038-2043. https://doi.org/10.1128/AEM.69.4.2038-2043.2003.

(62) Wang, X.; Sun, M.; Zhao, Y.; Wang, C.; Ma, W.; Wong, M. S.; Elimelech, M. In Situ Electrochemical Generation of Reactive Chlorine Species for Efficient Ultrafiltration Membrane Self-Cleaning. Environ. Sci. Technol. 2020, acs.est.0c01590.

https://doi.org/10.1021/acs.est.0c01590.

(63) Kotnik, T.; Frey, W.; Sack, M.; Haberl Meglič, S.; Peterka, M.; Miklavčič, D. ElectroporationBased Applications in Biotechnology. Trends Biotechnol. 2015, 33 (8), 480-488. https://doi.org/10.1016/j.tibtech.2015.06.002.

(64) El-Hag, A. H.; Jayaram, S. H.; Rodriguez Gonzalez, O.; Griffiths, M. W. The Influence of Size and Shape of Microorganism on Pulsed Electric Field Inactivation. IEEE Trans. Nanobioscience 2011, 10 (3), 133-138. https://doi.org/10.1109/TNB.2011.2163078.

(65) Guyot, S.; Ferret, E.; Boehm, J.-B.; Gervais, P. Yeast Cell Inactivation Related to Local Heating Induced by Low-Intensity Electric Fields with Long-Duration Pulses. Int. J. Food Microbiol. 2007, 113 (2), 180-188. https://doi.org/10.1016/j.ijfoodmicro.2006.06.036.

(66) Jeong, J.; Kim, J. Y.; Cho, M.; Choi, W.; Yoon, J. Inactivation of Escherichia Coli in the Electrochemical Disinfection Process Using a Pt Anode. Chemosphere 2007, 67 (4), 652-659. https://doi.org/10.1016/j.chemosphere.2006.11.035.

(67) Arkhipenko, M. V.; Nikitin, N. A.; Baranov, O. A.; Evtushenko, E. A.; Atabekov, J. G.; Karpova, O. V. Surface Charge Mapping on Virions and Virus-like Particles of Helical Plant Viruses. Acta Naturae 2019, 11 (4), 73-78. https://doi.org/10.32607/20758251-2019-11-4-73-78.

(68) Armanious, A.; Aeppli, M.; Jacak, R.; Refardt, D.; Sigstam, T.; Kohn, T.; Sander, M. Viruses at Solid-Water Interfaces: A Systematic Assessment of Interactions Driving Adsorption. Environ. Sci. Technol. 2016, 50 (2), 732-743. https://doi.org/10.1021/acs.est.5b04644. 